\title{
New-onset refractory status epilepticus (NORSE) in post SARS-CoV-2 autoimmune encephalitis: a case report
}

\author{
Fedele Dono ${ }^{1} \cdot$ Claudia Carrarini $^{1} \cdot$ Mirella Russo $^{1} \cdot$ Maria Vittoria De Angelis ${ }^{2} \cdot$ Francesca Anzellotti $^{3} \cdot$ Marco Onofrj $^{1}$. \\ Laura Bonanni ${ }^{1}$ (D)
}

Received: 12 August 2020 / Accepted: 17 October 2020 / Published online: 3 November 2020

(C) Fondazione Società Italiana di Neurologia 2020

\begin{abstract}
The 2019 new coronavirus (SARS-CoV-2) is a novel respiratory virus which has increasingly spread all over the world. Although the predominant clinical presentation is represented by respiratory symptoms, neurological manifestation of SARS-CoV-2 is being increasingly recognized. In the present report, we present a case of post SARS-CoV-2 autoimmune encephalitis associated with a new-onset refractory status epilepticus (NORSE).
\end{abstract}

Keywords COVID-19 · Epilepsy · Autoimmune encephalitis · Status epilepticus · Case report

\section{Introduction}

COVID-19 pandemic caused by the novel coronavirus (SARS-CoV-2) represents one of the largest emergencies that humanity had to be dealing with in the last century. Several reports indicate that SARS-CoV-2 infection can be associated with acute neurological manifestations [1]. Although the knowledge of central nervous system (CNS) acute comorbidities is increasing, little is known about the possible neurological sequelae of the infection. In the present report, we describe a case of post-SARS-CoV-2 autoimmune encephalitis presenting as new-onset refractory status epilepticus (NORSE).

Supplementary Information The online version contains supplementary material available at https://oi.org/10.1007/s10072-02004846-z.

Laura Bonanni

1.bonanni@unich.it

Fedele Dono

fedele.dono@alumni.unich.it

Claudia Carrarini

claudia.carrarini@alumni.unich.it

Mirella Russo

mirella.russo@alumni.unich.it

Maria Vittoria De Angelis

mavidea@yahoo.com

\section{Case presentation}

On May 12th, an 81-year-old man was admitted to the Emergency Department, due to persistent fever, mild dyspnea, and dry coughing started 7 days before the admission. His past medical history showed mild hypertension. Arterial blood gas analysis showed respiratory alkalosis (pH: 7.542) with normal blood oxygen saturation $\left(\mathrm{SO}_{2}: 94.6 \%\right)$, mild hypoxemia $(70.5 \mathrm{mmHg})$, and hypocapnia $(23.4 \mathrm{mmHg})$. Blood sample analysis documented slight lymphocytopenia, increased D-dimer $(1.23 \mathrm{mg} / \mathrm{ml})$, and normal level of procalcitonin and Creactive protein. Chest X-ray was unremarkable (Fig. 1a). Computed tomography (CT) scan of the lungs showed a ground-glass pattern in both the inferior lobe segments (Fig.

Francesca Anzellotti

f.anzellotti@libero.it

Marco Onofrj

onofrj@unich.it

1 Department of Neuroscience, Imaging and Clinical Science, "G. D’Annunzio" University of Chieti-Pescara, Chieti, Italy

2 Neurology Unit, "SS Annunziata University Hospital, Chieti, Italy

3 Department of Neurology, Epilepsy Center, Neurology Unit, "SS Annunziata" University Hospital, Chieti, Italy 
Fig. 1 Radiological findings. Chest X-ray (a) excluding signs of lobar pneumonia. Computed tomography (CT) of the lungs (b) showing ground-glass pattern in both the inferior lobe segments. Magnetic resonance imaging scans. Axial T2 fluid-attenuated inversion recovery (T2-FLAIR) (c-f) and axial diffusion-weighted imaging (DWI) $(\mathbf{g}, \mathbf{h})$ show hyperintense lesions of the bilateral parietal cortex, left temporal cortex, and right cingulate cortex
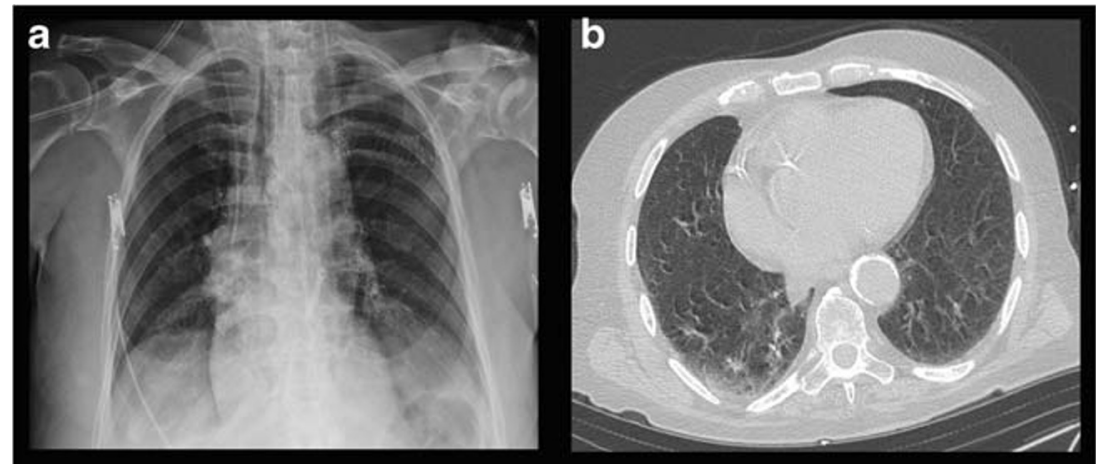

C

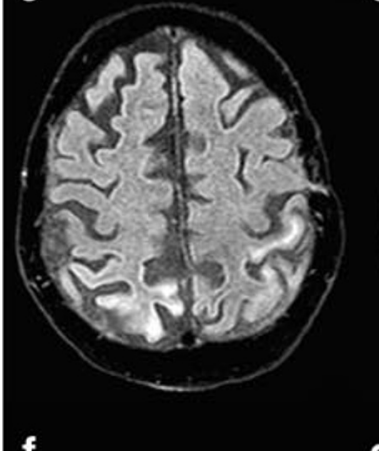

d

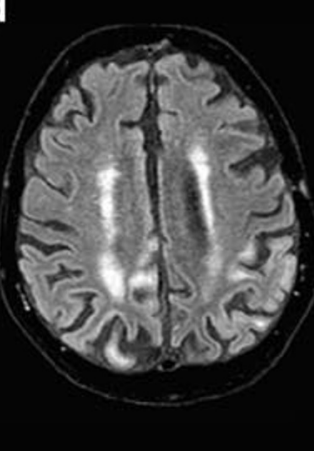

e $\mathbf{f}$

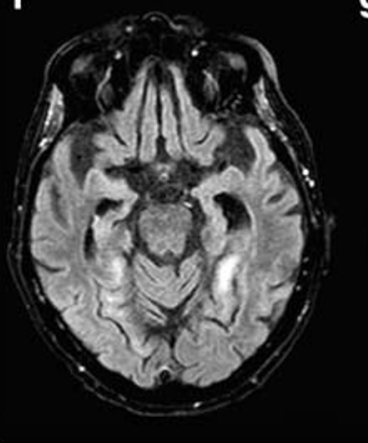

g

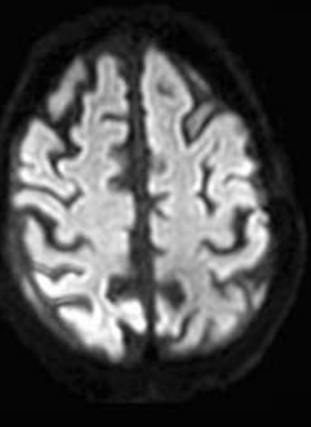

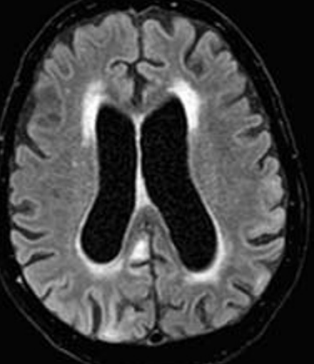

h

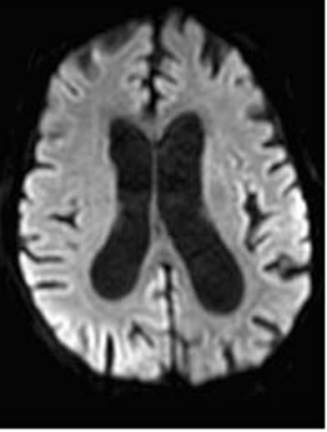

1b). Oropharyngeal and nasopharyngeal swabs were positive for SARS-CoV-2 infection. Hence, the patient was admitted to the COVID-19 Unit and empirically treated with azithromycin and supportive treatment with no need of oxygen therapy with relief of the symptoms in 14 days. Subsequently, two consecutive negative oropharyngeal and nasopharyngeal swabs confirmed the resolution of the acute SARS-CoV2 infection.

Since day 14, patient presented mild confusion with fluctuation of the mental status. An electroencephalogram (EEG) was performed with no evidence of epileptiform abnormalities (Fig. 2a). On day 16, patient became drowsy with Glasgow coma scale (GCS) of 5 (no eyes opening both to verbal and pain stimulation, no verbal response, and flexion of the upper limbs to pain). Contemporarily, frequent jerky myoclonic contractions of the abdomen and the right lower limb appeared. Laboratory tests excluded a wide range of encephalopathy causes, including hypoxia, drugs, toxins, and metabolic derangements. EEG recording showed continuous sharp waves and spike-and-slow-wave complexes at 2-2.5 Hz with superimposed fast activity predominantly lateralized over the left fronto-centro-temporal regions (lateralized periodic discharges plus superimposed fast activity, LPDs + F) (Fig. 2b). According to Salzburg criteria [2], a diagnosis of nonconvulsive status epilepticus with coma was made. A first therapeutic attempt with two intravenous (i.v.) boluses of Lorazepam $4 \mathrm{mg}$ followed by a i.v. bolus of Levetiracetam $2000 \mathrm{mg}$ and Perampanel $20 \mathrm{mg}$ via nasogastric tube was made with a good electroclinical response in the first $48 \mathrm{~h}$ (no myoclonic jerks were detectable). On day 19, myoclonic contractions reappeared accompanied by EEG worsening, represented by $2-2.5 \mathrm{~Hz}$ LPDs + F pattern. Therefore, patient was transferred to intensive care unit and treated with general anesthesia with midazolam $0.2 \mathrm{mg} / \mathrm{kg}$ under continuous EEG monitoring. He received further anti-seizure medication treatments with i.v. Valproate (1600 mg/day) and Lacosamide 
a

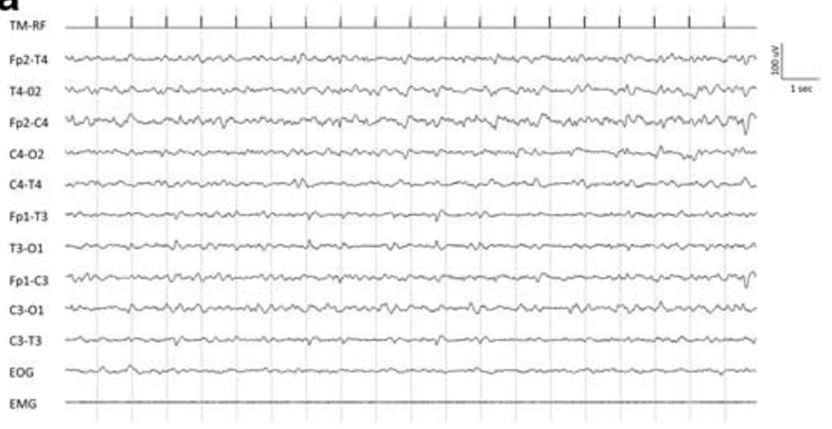

b

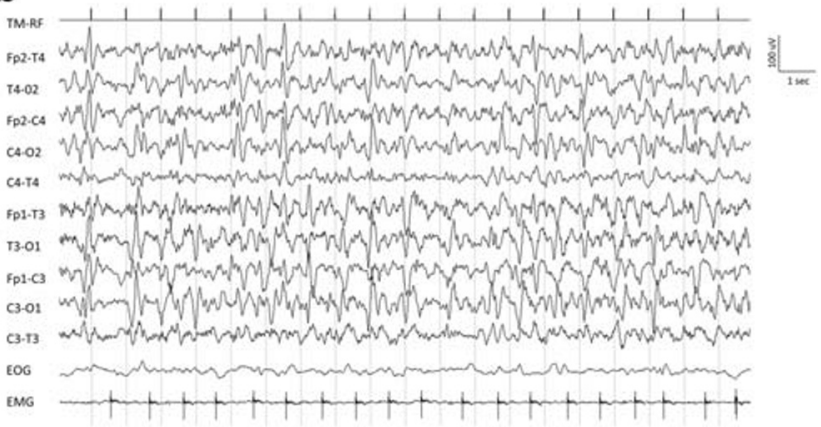

C

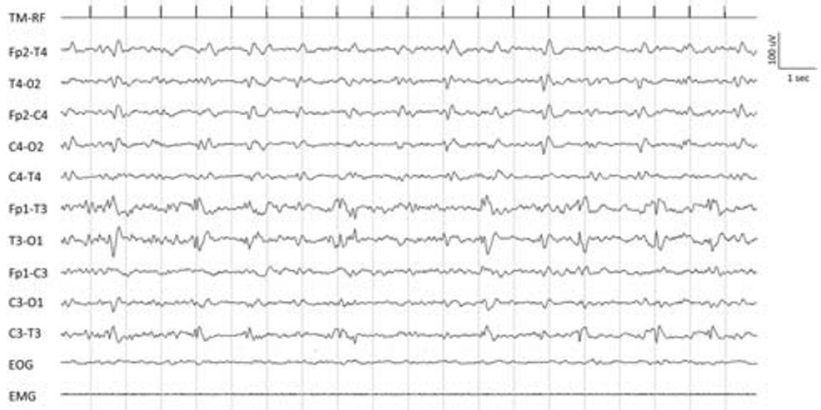

Fig. 2 Electroencephalogram findings. a EEG performed on day 14 showing a background slowing. b Ictal EEG performed on day 16 showing continuous sharp waves and spike-and-slow-wave complexes at $2-2.5 \mathrm{~Hz}$ and $100-150 \mathrm{mV}$ of amplitude with superimposed fast activity predominantly lateralized over the left fronto-centro-temporal regions (lateralized periodic discharges plus superimposed fast activity, LPDs + F pattern). $\mathbf{c}$ Interictal EEG performed on day 32 showing lowamplitude spikes and sharp waves predominantly lateralized over the left temporal region

(400 mg/day). On the following days, clinically and electrical seizure control was obtained. On day 23 , after anesthesia interruption, recurrence of EEG abnormalities and jerks in the abdomen and right lower limb were observed. Patient underwent a magnetic resonance imaging (MRI) of the brain which showed multiple hyperintense areas in T2 fluidattenuated inversion recovery (T2-FLAIR) and axial diffusion-weighted imaging (DWI) in the bilateral parietal cortex, left temporal cortex, and right cingulate cortex with no contrast enhancement after gadolinium injection (Fig. 2ch). No signs of cerebral thrombosis have been detected according to magnetic resonance angiography and venography sequences. Cerebrospinal fluid (CSF) examination showed lymphocytosis $\left(26 \mathrm{cell} / \mathrm{mm}^{3}\right)$, normal glucose level $(78 \mathrm{mg} /$ $\mathrm{dl})$, slight protein increase $(47 \mathrm{mg} / \mathrm{dl})$, and positive oligoclonal bands (OCB). Polymerase chain reaction (PCR) for SARSCoV-2, herpes simplex viruses (HSV-1, HSV-2, HHV-6, HHV-7, HHV-8), cytomegalovirus, Epstein-Barr virus, and varicella zoster virus in the CSF was negative.

Despite that the autoimmune panel for encephalitis, performed both on serum and CSF, was negative (Table 1 of the Supplementary material), a diagnosis of possible autoimmune encephalitis was made according to Graus criteria [3]. Patient was treated with steroids (i.v. methylprednisolone $1 \mathrm{~g}$ /daily for 5 days followed by oral prednisolone $60 \mathrm{mg} /$ day for 10 days) and i.v. immunoglobulins ( $160 \mathrm{~g}$ over 5 days). On day 32, EEG recording showed no seizure recurrence, even though interictal epileptiform abnormalities were still present (Fig. 2c). Five days later, patient opened eyes to pain with no verbal response, showing flexion of the upper limbs to pain (GCS: 6). No myoclonic jerks were detectable. Any side effects due to all treatments were not observed. MRI after treatment was not performed due to patient's critical condition. After day 37, patient condition deteriorated due to nosocomial pneumonia. Patient developed sepsis and died on day 45 due to cardiac arrest.

\section{Discussion}

The possible coronaviruses neuro-invasive capabilities in humans were previously suggested [4]. Upon nasal infection, coronaviruses enter the CNS through the olfactory bulb, causing inflammation and demyelination [4]. A growing number of case reports and series describe a wide array of neurological manifestations in the context of SARS-CoV-2 infection [4]. Recently, eight cases [1, 5-9] of encephalitis associated with COVID-19 have been reported, in which irritability, confusion, drowsiness, and new-onset epilepsy represent the main symptoms at onset.

In our report, we describe a case of severe encephalitis associated with NORSE. Several differential diagnoses, including metabolic and viral encephalitis, cerebral thrombosis, posterior reversible encephalopathy (PRES), acute disseminated encephalomyelitis (ADEM), and cerebral vasculitis, were excluded before making the diagnosis of possible autoimmune encephalitis (Table 2 of the Supplementary material). The strict time correlation between SARS-CoV-2 infection, neurological symptoms onset, and negative PCR for other viruses on CSF suggests a possible causative role of the SARS-CoV-2 infection in the development of post-acute autoimmune response, dramatically appearing with NORSE. NORSE is a syndrome in which status epilepticus manifests in previously healthy patients without a history of epilepsy or other neurological disorders [10]. Autoimmune etiology is generally recognized [10]. The outcome is commonly fatal or burdened by severe neurological sequelae [10]. 


\section{Conclusion}

Our report confirms the importance of evaluating neurological sequelae in post-acute phase of SARS-CoV-2 infection.

Acknowledgments The authors thank prof. Massimo Caulo for MRI scan acquisition and interpretation.

\section{Compliance with Ethical Standards}

Conflict of interest None.

Ethical approval None.

Informed consent An informed consent was obtained from the patient's daughter, due to the severe medical condition of the patient himself.

\section{References}

1. Ellul MA, Benjamin L, Singh B, et al (2020) Neurological associations of COVID-19 [published online ahead of print, $2020 \mathrm{Jul} 2$ ]. Lancet Neurol S1474-4422(20):30221-0. https://doi.org/10.1016/ S1474-4422(20)30221-0

2. Leitinger M, Beniczky S, Rohracher A, Gardella E, Kalss G, Qerama E, Höfler J, Hess Lindberg-Larsen A, Kuchukhidze G, Dobesberger J, Langthaler PB, Trinka E (2015) Salzburg Consensus Criteria for Non-Convulsive Status Epilepticusapproach to clinical application. Epilepsy Behav 49:158-163. https://doi.org/10.1016/j.yebeh.2015.05.007

3. Graus F, Titulaer MJ, Balu R, Benseler S, Bien CG, Cellucci T, Cortese I, Dale RC, Gelfand JM, Geschwind M, Glaser CA, Honnorat J, Höftberger R, Iizuka T, Irani SR, Lancaster E, Leypoldt F, Prüss H, Rae-Grant A, Reindl M, Rosenfeld MR, Rostásy K, Saiz A, Venkatesan A, Vincent A, Wandinger KP, Waters P, Dalmau J (2016) A clinical approach to diagnosis of autoimmune encephalitis. Lancet Neurol 15(4):391-404. https:// doi.org/10.1016/S1474-4422(15)00401-9

4. Desforges M, Le Coupanec A, Dubeau P et al (2020) Human coronaviruses and other respiratory viruses: underestimated opportunistic pathogens of the central nervous system? Viruses 12:14. https://doi.org/10.3390/v12010014

5. Vollono C, Rollo E, Romozzi M, Frisullo G, Servidei S, Borghetti A, Calabresi P (2020) Focal status epilepticus as unique clinical feature of COVID-19: a case report. Seizure 78:109-112. https:// doi.org/10.1016/j.seizure.2020.04.009

6. Pilotto A, Odolini S, Stefano Masciocchi S et al (2020) Steroidresponsive encephalitis in Coronoavirus disease 2019. Ann Neurol 88:423-427. https://doi.org/10.1002/ana.25783

7. Bernard-Valnet R, Pizzarotti B, Anichini A et al (2020; published online May 7) Two patients with acute meningo-encephalitis concomitant to SARS-CoV-2 infection. Eur J Neurol. https://doi.org/ 10.1111/ene. 14298

8. Moriguchi T, Harii N, Goto J, Harada D, Sugawara H, Takamino J, Ueno M, Sakata H, Kondo K, Myose N, Nakao A, Takeda M, Haro H, Inoue O, Suzuki-Inoue K, Kubokawa K, Ogihara S, Sasaki T, Kinouchi H, Kojin H, Ito M, Onishi H, Shimizu T, Sasaki Y, Enomoto N, Ishihara H, Furuya S, Yamamoto T, Shimada S (2020) A first case of meningitis/encephalitis associated with SARS-Coronavirus-2. Int J Infect Dis 94:55-58. https://doi.org/ 10.1016/j.ijid.2020.03.062

9. Wong PF, Craik S, Newman P et al (2020; published online May 5) Lessons of the month 1: a case of rhombencephalitis as a rare complication of acute COVID-19 infection. Clin Med (Lond). https://doi.org/10.7861/clinmed.2020-0182

10. Gaspard N, Foreman BP, Alvarez V, Cabrera Kang C, Probasco JC, Jongeling AC, Meyers E, Espinera A, Haas KF, Schmitt SE, Gerard EE, Gofton T, Kaplan PW, Lee JW, Legros B, Szaflarski JP, Westover BM, LaRoche SM, Hirsch LJ, For the Critical Care EEG Monitoring Research Consortium (CCEMRC) (2015) Newonset refractory status epilepticus: etiology, clinical features, and outcome. Neurology. 85(18):1604-1613. https://doi.org/10.1212/ WNL.0000000000001940

Publisher's note Springer Nature remains neutral with regard to jurisdictional claims in published maps and institutional affiliations. 